\title{
Plant biologists fear for cress project
}

\section{Is enthusiasm withering for funding studies into Arabidopsis thaliana?}

The brilliant career of a diminutive weed may have hit a snag. Arabidopsis thaliana has been the darling of plant biologists for some 30 years because of its small genome and rapid growth, and in 2000 it became the first plant to have its genome sequenced. To capitalize on this, the US National Science Foundation (NSF) soon afterwards dedicated US\$200 million towards determining the function of every Arabidopsis gene by 2010.

Now time is nearly up, although the work is far from done. And with the NSF unlikely to extend the project, Arabidopsis researchers fear that the plant's popularity with funders is on the wane.

The appeal of Arabidopsis is as a stand-in for unwieldy food crops that grow slowly, take up lots of space and have large genomes. By studying thousands of plants in a single greenhouse, scientists can conduct experiments in a fraction of the time and space required for crop species. But sequencing technology is improving so quickly that genome size is no longer the barrier it once was. As more crop genomes are sequenced, including maize (corn) and rice, researchers can increasingly study crop species directly, rather than relying on a model plant.

"There's obviously a drive back to increased funding of crop plant research," says Mark Stitt at the Max Planck Institute of Molecular Plant Physiology in Potsdam, Germany. "This is fair and good, but there is a quite serious risk that some of the advances made in Arabidopsis research in the past ten years may not be sustained."

Data from the NSF's 2010 project (see 'Inside Arabidopsis' for a few highlights) have been used to tackle fundamental questions about development, pathogen resistance and hormone signalling. Annotation of the Arabidopsis genome - the linking of biological data to sequence information - is now considered among the highest quality of all sequenced genomes.

But the project has fallen short of its original goal of determining the function of every gene. Most Arabidopsis genes have been characterized in some fashion, for instance by observing their expression in a high-throughput assay, says Eva Huala, director of the Arabidopsis Information Resource (TAIR), a database at the Carnegie Institution of

\author{
INSIDE ARABIDOPSIS \\ The Arabidopsis 2010 project has linked \\ thousands of the plant's genes and proteins \\ to their biological function.
}

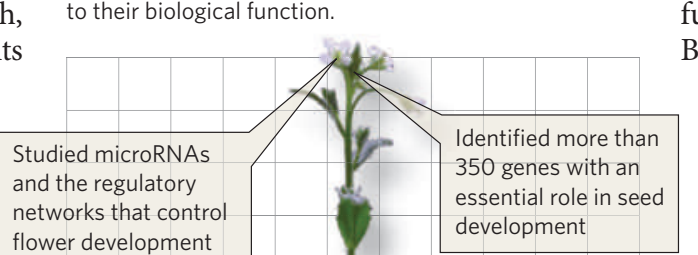
essential role in seed flower development

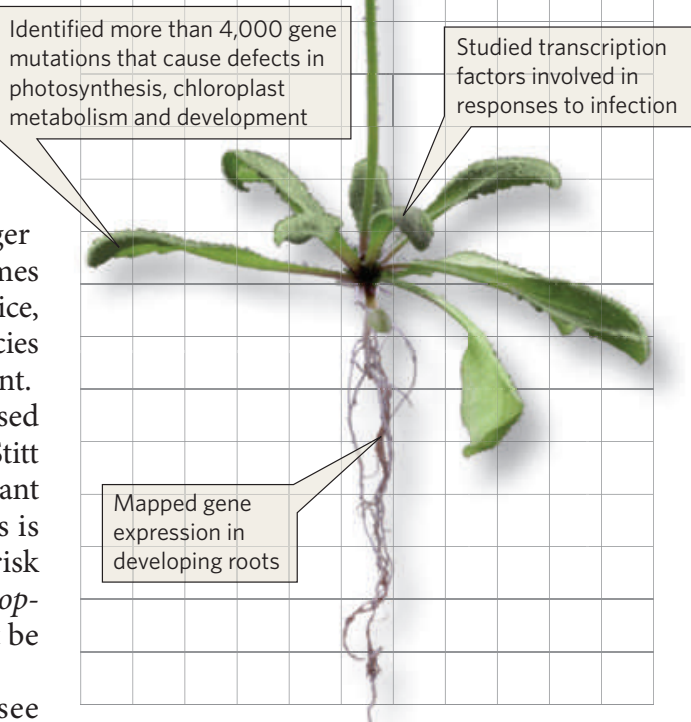

Washington in Stanford, California. However, Huala estimates that direct experimental data about function are available for only a third of all Arabidopsis genes.

Money was one hurdle.

"People seem to feel, 'Oh, Arabidopsis is done. Let's just move to the real stuff.' Well, it's not done." Although the project was designed for an annual budget of $\$ 100$ million, it actually received about a fifth of that sum. Then there were biological obstacles. Arabidopsis has many large gene families whose constituent genes have overlapping functions - a common phenomenon in plants. Knocking out one gene in the family often did not affect the plant, because other genes were able to compensate. "When the programme was designed, there was this idea that if we march through every gene and look at its phenotype with a knockout mutant, that would give us great insight into the functional identity of every gene," says Philip Benfey, a plant biologist at Duke University in Durham, North Carolina. "The reality was much more complicated."

\section{Systems approach}

In 2008, the project team drafted a proposed Arabidopsis 2020 programme that would focus on systems biology, an approach that would use the large data sets generated in the 2010 programme to develop models of plant function.

That programme, however, is unlikely to be funded, according to Parag Chitnis, deputy director of the NSF's Division of Molecular and Cellular Biosciences. "Now we are thinking beyond just one model organism," he says.

The NSF's Plant Genome Research Program and the Department of Agriculture's competitive funding programme have increasingly favoured grants for work on agricultural species in recent years. The NSF has also begun phasing out funding for TAIR, which is partially funded by 2010 project funds (see Nature $\mathbf{4 6 2}$, 258-259; 2009).

"People seem to feel, 'Oh, Arabidopsis is done. Let's just move to the real stuff," says Natasha Raikhel at the University of California, Riverside. "Well, it's not done." Raikhel adds that researchers have only just begun to tackle some key biological questions in Arabidopsis, such as how cell walls form. Researchers developing ways to turn cellulose into ethanol need to know how plants build their cell walls, but it is often more difficult to characterize the function of genes in biofuel crops.

And although Benfey welcomes additional funding for crop research, he notes that the extensive data already available for Arabidopsis make it the best species to advance plant systems biology. It would be difficult to build general models of flowering, for example, using data collected from many different plants, he says.

Even crop researchers have a good word for the little weed. "It's very important for the entire plant and agricultural community that Arabidopsis research should continue to be funded." says Edward Buckler, a maize geneticist at Cornell University in Ithaca, New York.

Heidi Ledford 